\title{
Influence of Parenting Style on the Visually Impaired Adolescents and Their Self-Esteem - Analysis Based on A Saudi Population
}

\author{
Ferial M Al-Zeraid ${ }^{1}$, Sedeeq Abeer ${ }^{1}$ and Osuagwu Uchechukwu ${ }^{2 *}$ \\ ${ }^{1}$ Department of Optometry \& Vision Sciences, College of Applied Medical Sciences, King Saud University, Riyadh, P.O. Box 10219, \\ Riyadh, 11433 Saudi Arabia
}

${ }^{2}$ Osuagwu Uchechukwu Levi, School of Medicine, Australia

*Corresponding author: Osuagwu Uchechukwu, School of Medicine, Diabetes Obesity \& Metabolism Translational Research Unit (DOMTRU), Australia

\section{ARTICLE INFO}

Received: 峯 July 13, 2019

Published: July 22, 2019

Citation: Ferial M Al-Zeraid, Sedeeq Abeer, Osuagwu Uchechukwu. Influence of Parenting Style on the Visually Impaired Adolescents and Their SelfEsteem - Analysis Based on A Saudi Population. Biomed J Sci \& Tech Res 19(5)-2019. BJSTR. MS.ID.003363.

Keywords: Parenting style; Visual impairment; Blindness; Self-Esteem; Low vision

\section{ABSTRACT}

Purpose: To investigate the attitude of visually impaired adolescents, towards parents and examine the parents' attitudes toward the visually impaired child. We also assessed the effects of the parenting styles on the self-esteem of the visually impaired adolescent.

Methods: Buri's parental authority questionnaire was completed by children and their parents and used to assess the perceived parental style of both groups. The short form of the Tennessee Self-Concept Scale (sort form) [TSCS-2] completed by 125 children and 250 parents of visually impaired school and public schools in Riyadh Central province of Saudi Arabia. Of the students who responded (39/125, 31.2\%), 21 were males and 18 females and their age ranged from 13 to 18 years (mean age, 15 years). Of the parents who responded $(119 / 250,47.6 \%), 58$ were males and 61 females and their age ranged from 19 to 36 years $($ mean $=27)$.

Results: Parental Authority Questionnaire showed that more than one-half of the adolescents perceived parenting as authoritative (57\%) and the remaining perceived parenting as either authoritarian $(28 \%)$ or permissive $(15 \%)$ but the differences was not significant (ANOVA: $\mathrm{P}<0.80$ ) and remained unaffected by the students' gender $(\mathrm{P}>0.05)$. The associations between the Tennessee Self Concept Score (TSCS) and the parenting styles was at borderline significance only for authoritative parenting style $(\mathrm{P}=0.08, \mathrm{r}=0.28)$. The levels of self-esteem were higher in males than female (69\%vs $31 \%$ ) students. There was no difference in responses between students who attended public schools and those in the visually impaired school.

Conclusion: The majority of visually impaired adolescents perceived parents as authoritative, had higher self-esteem than the fewer students with either authoritarians or permissive parents and had lower self-esteem. Further testing to elicit separate responses for mothers and fathers parenting styles could help reinforce these findings.

\section{Introduction}

Visual impairment in the form of low vision or blindness affects more than 161 million of whom about 37 million are blind and mostly adults [1]. Visually impaired young adults are at risk of reduced participation and social exclusion [2,3]; have fewer friends and feel lonely compared with the sighted person [4-7]; and have a longer childhood than their peers probably due to overprotectiveness of their parents and helpers or lack of assistive devices [8]. Compared with sighted persons, the visually impaired adult shows no differences in the frequency of depression, distress symptoms, relations with parents and siblings and in level of selfesteem, but the relationship with friends enhances the self-esteem of the visually impaired adult $[2,4]$. The disability of one family member was reported to affect the whole family, and for several years after the diagnosis [9]. Parents and family members of the 
visually impaired persons experience increase in stress levels mainly due to the additional demands posed by caring for the visually impaired person. This in turn, influences their attitude towards the child $[9,10]$. The attitude of the parents and family members towards the visually impaired person is a great source of social support $[4,11]$ particularly because the adolescent needs more concern from their parents, for future education and school support [12]. The visually impaired adolescents have fewer leisure activities and are more dependent on parents for daily activities than their sighted peers [13]. Peer and parental support are important for well-being of both adolescents with a visual impairment and sighted adolescents [14]. Past studies [15,16] found that the parenting style affect the behavior of children and their interaction with the society. Baumrind [16] introduced the parenting styles typology. She identified three parenting styles including:

a) Authoritarian parenting in which parents are very restrictive and impose rules on the children while the child in return strictly obeys the rules but the parents failed to offer explanations on why the child needs to comply with the rules. In this parenting style, the parents rely on punitive, forceful tactics such as power assertion or love withdrawal, to ensure compliance

b) Authoritative parenting which is a more flexible parenting compared with the previous style. In this, the child has considerable freedom and is expected to comply with imposed restrictions. However, the parents provide rationales for such imposed restrictions and could use power, if necessary, and reason (inductive discipline), to ensure that the children comply with the restrictions.

In permissive parenting, the parents make relatively few demands from the child who is permitted to do most activities, and they rarely exert firm control over the child's behavior. Children raised by authoritative parents are often energetic, friendly, cheerful, socially responsive, self -reliant, achievementoriented, and cooperative whereas those raised by authoritarian parents are conflicted-irritable, moody, unhappy, easily annoyed, relatively aimless, and unfriendly. The impulsive-aggressive, bossy, self-centered, rebellious, aggressive are characteristics of children raised by permissive parents. The children are also low in independence and achievement [15]. The parenting style is related to the adolescent's goal orientation and school achievement [17]. The large differences, for example, in communication and adaptive skills, both within and between groups of people with impairments, makes it logical to expect that certain groups will encounter more difficulties in their attempt to integrate than other groups [18] The variation in attitude towards different categories of disabled people result from cultural values, environmental influences, age and exposure of disabled people [19]. It is important to have a community-specific data. While there have been numerous studies in the past linking several variables to the development of self-esteem in normally sighted children, adolescents and young adults $[15,16]$, investigations into the influence of different parenting styles on the child's personality and behavior have shown conflicting findings considering only the normally-sighted individuals. Visually impaired individuals are two times more likely to report being depressed [20] and according to World Health Organization, depression as a form of mental illness is a major cause of suicide[21]. In this study, we investigated the attitude of the visually impaired adolescents, towards their parents and examined the parents' attitudes toward the visually impaired child. In addition, we also assessed the effects of the parenting styles on the attitude/self-esteem of the visually impaired adolescent.

\section{Materials and Methods}

\section{Ethics}

Approval for this study was obtained from the Ministry of Education and the Research Ethics Committee of the College of Applied Medical Sciences, and the study was performed in accordance with the Declaration of Helsinki of 1975, as revised in 2000. Informed and written consent was obtained from all participating parents and students, prior to enrollment, after the study protocol (and their rights as participants) had been explained to them in class and in the envelop sent out to the parents. Filling in the questionnaire was voluntary and anonymous and did not affect their grades or participation in the class. Data were collected and stored anonymously.

\section{Study Sample and Procedure}

Participants were recruited from parents and students of 10 out of the 20 public schools that were contacted to participate including one special school (Al-Noor Institute for the visually impaired and blind persons). The study was conducted between July and September 2016. A total of 375 questionnaires were sent out to students $(n=125)$ and parents $(n=250)$ of these schools. Of the students who responded (39/125, 31.2\%), 21 were males and 18 females and their age ranged from 13 to 18 years (mean $=15)$. Of the parents who responded (119/250, 47.6\%), 58 were males and 61 females and their age ranged from 19 to 36 years (mean $=27$ ). The school children were contacted through the administration and the questionnaires were sent out in sealed envelopes (one labelled 'child' and the other 'parent') banded together. The envelopes were given to each student and they were asked to return the envelope to their class teachers on completion. For a family unit with mother and father, an extra parent envelope was given. Each envelope contained a cover letter describing the reasons for the study, a stamped, preaddressed, coded postcard and the questionnaire. Use of postcards ensured confidentiality of individual's responses. Both child and parent were administered the parental authority questionnaire [22], but only the child received the Tennessee self-concept scale questionnaire [23]. All participating students were asked to fill in the questionnaires in class and hand them in to the teachers. 


\section{Questionnaires}

Assessment of Parenting Style in Visually Impaired Adolescents and their Parents: Buri's parental authority questionnaire which was completed by children and their parents in this study is a convenient and effective reliable tool for evaluation of attitude towards people with disabilities [22]. It consists of 30 items expressed as statements to which respondents answer on a Likert-type scale. The participants were asked to indicate in whether he/she strongly disagrees, disagrees, is undecided, agrees or strongly agrees with each statement. The questionnaire measured the children's perceptions of household dynamics. For example, in Question number 8, participants were asked to react to the statement, "As I was growing up, my parents did not allow me to question any decision that they had made". It also measured the children's perception of their parents' attitudes, such as Question number 12, "my parents feel that most problems in society would be solved if parents would not restrict children's decisions and desires as they are growing up". For the parents, this questionnaire was slightly modified to address the aims of this study. For example, the above Questions were changed to "As our children were growing up, we did not allow them to question any decision that we had made" and "I feel the most problems in society would be solved if parents would not restrict children's decisions and desires as they are growing up". The information that was elicited from this questionnaire yielded an identification of their parenting styles and provided information on visually impaired adolescents' attitudes toward their parents. There were no 'right' or 'wrong' answers and no time limit.

Assessment of Self Esteem: The short form of the Tennessee Self-Concept Scale (sort form) [TSCS-2] was completed only by the children. It consists of 20 items used to evaluate self-esteem and abilities. Questions were designed to assess the students' responses of moral, physical and personal self-concept and how the respondents see themselves in many aspects of life including family, social, school and job sitting as well as an overall score. The student was asked to indicate whether he/she agrees or disagrees with each statement. Commonly, five options are provided: "always false," "mostly false," "partly false," "partly true," "mostly true". For example, Question number 41 which read, "I do not feel at ease with other people" was directed to assess their self-esteem and Question number 42 which read, "Math is hard for me" was inquiring on their abilities. The questionnaire was modified to suit the visually impaired population and the modification included constructing one version of the questionnaire in large-print type (24-point Times new Roman). This version of the survey contained only one or two questions per page. The survey was also converted into Grade II Braille through the Blind Association and the Braille version was sent with an instruction sheet describing how the respondents were to provide their answer.

Data Analysis: Incomplete questionnaires were not included in the analysis. The results were entered into a Microsoft Excel spreadsheet, overlaid to eliminate data errors and corrected. Analysis was performed using the SPSS statistical software version 16.0 (SPSS Inc., Chicago, USA). The scoring system was performed in a similar manner to that used in our previous study [24] for each numerical grade in the questionnaire. Frequency distribution graphs were used for analysis.

\section{Results}

A hundred and fifty-eight children and parents responded to the questionnaires resulting in a response rate of $42.1 \%$ ( $n=$ 158/375). Thirty-five and 90 adolescent surveys were sent to the Al-Noor school for the blind \& visually impaired, and some public schools, respectively. Higher proportion of students who attended the Al-Noor institute for the blind and Visually impaired responded to the survey $(40 \%, 14 / 35)$ compared to students who attended public schools (27.8\% respondents, 25/90). Table 1 presents the demography of the participants showing that majority of the adolescents were less than 15yrs of age, attended public schools and had 3 or more siblings. For the parents, majority were married at the time of this study, unemployed, had no other child with disability and had a monthly family income of less than 10,000 SR (approx. US\$2,700). Analysis from the Parental Authority Questionnaire showed that more than one-half of the adolescents perceived parenting as authoritative $(\overline{\mathrm{x}}=37.3,56.4 \%)$ and the remaining $43.6 \%$ perceived parenting as either authoritarian $(\overline{\mathrm{x}}$ $=32.5,28.2 \%)$ or permissive $(\bar{x}=30.33,15.38 \%)$. The student's perception of parenting styles was not significantly different on analysis using repeated measures ANOVA ( $\mathrm{F}=0.068, \mathrm{df}=38, \mathrm{P}<$ 0.796) (see Figure 1) and unaffected by age of the adolescents ( $p>0.05$, for all perceived parental styles). The association between the mean of Tennessee Self Concept Score (TSCS) and the different parenting styles examined using Pearson correlation showed no significant relationship for authoritarian $(\mathrm{r}=0.007, \mathrm{P}=0.977)$ and permissive parenting style ( $\mathrm{P}=0.967, \mathrm{r}=-0.005$ respectively), but a close to significant relationship for authoritative parenting style $(\mathrm{P}=0.083, \mathrm{r}=0.281$ ) (Figure 1). 


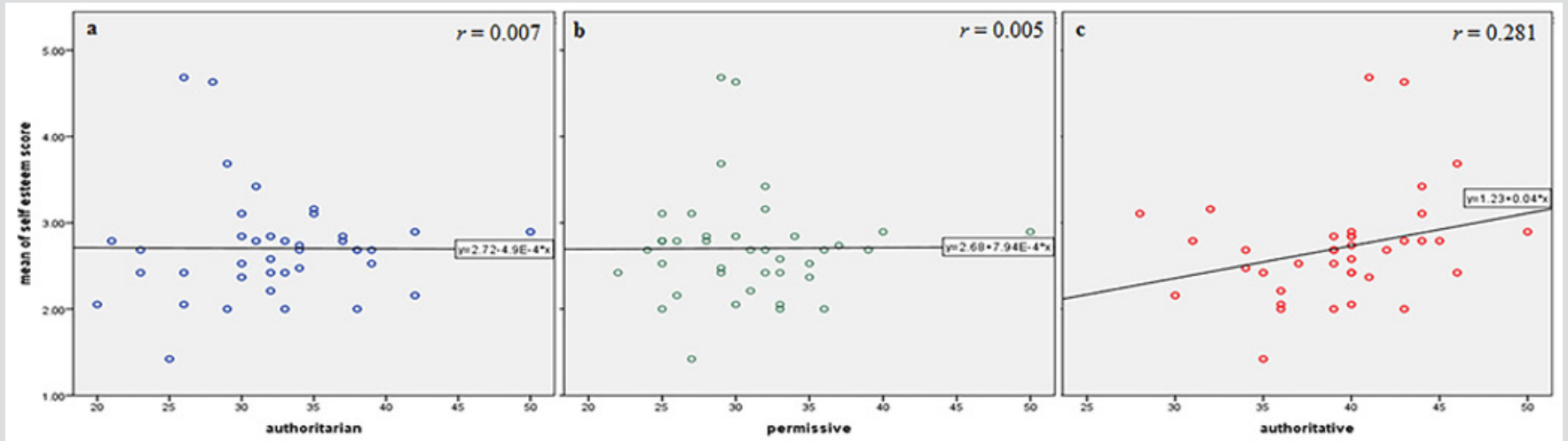

Figure 1: Correlation between the mean of Tennessee Self Concept Score (TSCS) and parenting style. Report from 39 school children.

Table 1: Sociodemographic characteristics of the study respondents.

\begin{tabular}{|c|c|c|}
\hline Sociodemographic Characteristics & $\mathbf{N}$ & $\%$ \\
\hline \multicolumn{3}{|c|}{ Children (n = 39) } \\
\hline \multicolumn{3}{|l|}{ Age group } \\
\hline$<15$ yrs & 21 & 53.8 \\
\hline $15-18$ yrs & 12 & 30.8 \\
\hline$>18$ yrs & 6 & 15.4 \\
\hline \multicolumn{3}{|l|}{ Gender } \\
\hline Male & 21 & 53.8 \\
\hline Female & 18 & 46.2 \\
\hline \multicolumn{3}{|l|}{ Type of School attended } \\
\hline School for the Visually impaired & 14 & 35.9 \\
\hline Public School & 25 & 64.1 \\
\hline \multicolumn{3}{|l|}{ Birth-order } \\
\hline first & 5 & 12.8 \\
\hline last & 4 & 10.3 \\
\hline others & 30 & 76.9 \\
\hline \multicolumn{3}{|l|}{ Number of siblings } \\
\hline None & 1 & 2.6 \\
\hline 2 & 2 & 5.1 \\
\hline 3 or more & 36 & 92.3 \\
\hline \multicolumn{3}{|l|}{ Parents (119) } \\
\hline \multicolumn{3}{|l|}{ Age group } \\
\hline 25-34 years & 21 & 16.0 \\
\hline $35-44$ years & 12 & 31.9 \\
\hline $45-54$ years & 6 & 35.3 \\
\hline$\geq 55$ years & & 16.8 \\
\hline \multicolumn{3}{|l|}{ Gender } \\
\hline Male & 58 & 48.7 \\
\hline Female & 61 & 51.3 \\
\hline \multicolumn{3}{|l|}{ Marital Status } \\
\hline Married & 113 & 95.0 \\
\hline Not married & 6 & 5.0 \\
\hline \multicolumn{3}{|l|}{ Occupation } \\
\hline Employed & 11 & 9.2 \\
\hline
\end{tabular}

\begin{tabular}{|c|c|c|}
\hline Not employed/business owner & 108 & 90.8 \\
\hline Level of education & & \\
\hline $\begin{array}{c}\text { Primary/secondary education } \\
\text { Tertiary education (College/university/ } \\
\text { postgraduate) }\end{array}$ & 24 & 20.2 \\
\hline $\begin{array}{c}\text { Total family income } \\
<10,000 \text { SR }\end{array}$ & 88 & 73.9 \\
\hline$\geq 10,000$ SR & 31 & 26.1 \\
\hline Presence of other child with disability & & \\
\hline Yes & 9 & 7.56303 \\
\hline No & 109 & 91.5966 \\
\hline
\end{tabular}

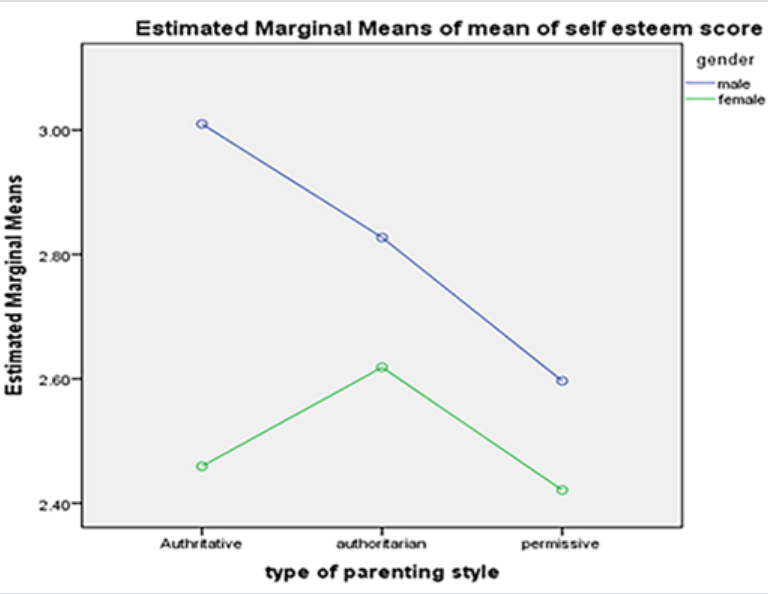

Figure 2: Difference between male and female Teneesse Self-Concept Score (TSCS) for the three types of parenting style.

Figure 2 is a profile plot of adolescent's attitude for male and female students, represented as the mean score plotted as a function of parenting styles. There was no gender-based differences in the adolescent's attitudes toward their parents (two-way analysis of variance, $p=0.688$ ). The results of the Tennessee Self-Concept Scale (TSCS) were examined by independent t-test to determine if there was a difference in mean self-concept score between male and female students. The mean score of the TSCS for female students 
(2.89) was significantly greater than the males $(2.49, \mathrm{P}=0.044)$ (Figure 3). The levels of self-esteem measured by the median of the TSCS (51) showed higher level of self-esteem (68.8\%) for males than for females (31.3\%) who had higher low self-esteem level than males (54.5\% versus $45.5 \%$, respectively). The mean TSCS score did not vary between public schools and visually impaired school $(\mathrm{P}=0.129)$. It was 2.81 for public school students and 2.50 for the visually impaired school students (Figure 4). Analysis of the parents' responses for the Parental Authority Questionnaire, showed similar trend as was observed for the adolescents' responses. Many of the parents indicated that they were authoritative $(\overline{\mathrm{x}}=39.3)$ while others felt they were authoritarian $(\overline{\mathrm{x}}=32.1)$ or permissive $(\overline{\mathrm{x}}$ $=31.0$ ). However, while there was no significant difference between the parents' responses on the parental style $(\mathrm{p}<0.356, \mathrm{~F}=.858 \mathrm{df}$ =118), the age of the parents had a significant effect only among parents who were perceived as being authoritarian $(\mathrm{p}<0.025, \mathrm{~F}=$ 3.248, $\mathrm{df}=118$ ) and authoritative $(\mathrm{p}<0.036, \mathrm{~F}=2.948$, $\mathrm{df}=118)$. Post hoc analysis revealed significant differences between the responses of perceived authoritarian parents aged between 45 to 55 years and the younger parents (ages 25-34 years, $p=.17$, and 35 -
44 years, $\mathrm{p}=.07)$. Similar effects of age were found for the responses of parents who were perceived as authoritative but this time the difference was between the elder parents ( $>55 \mathrm{yrs}$ ) and the younger parents (ages 25-34 years, $\mathrm{p}=.024$, and $35-44$ years, $\mathrm{p}=.015$ ).

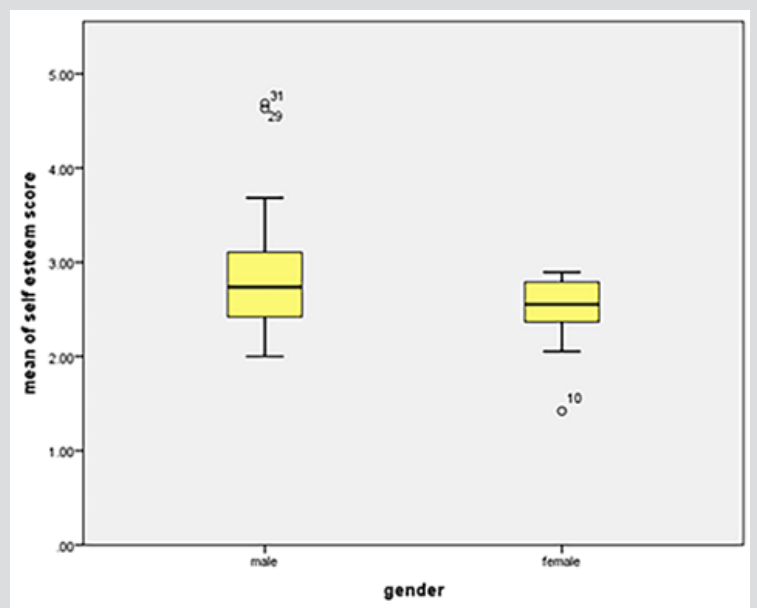

Figure 3: Means of Teneesse Self-Concept Score (TSCS) for male and female adolescents.

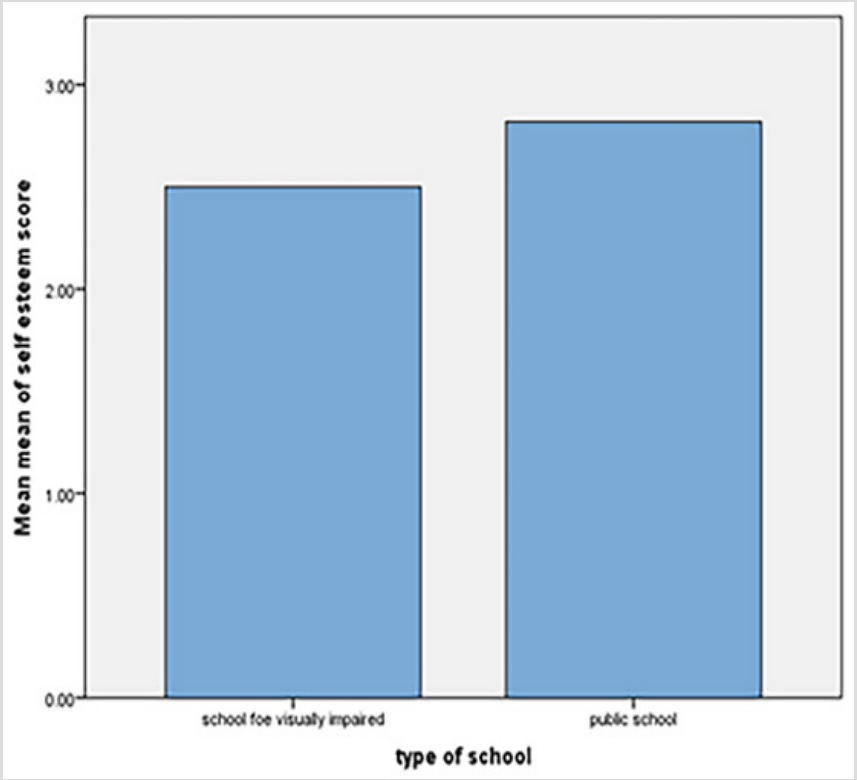

Figure 4: The mean Tennessee Self Concept Score (TSCS) for the different schools (visually impaired school and public schools).

\section{Discussion}

In this study, majority of the students perceived their parents as authoritative, had higher scores for self-esteem and improved competence scores than those who considered their parents as authoritarian or permissive. This was consistent with Baumrind [16] finding in normal sighted persons. Although, we did not find a significant correlation between parenting styles and the level of selfesteem, we can deduce that the style of parenting described by the majority of visually impaired adolescents and parents matches the definition for authoritative parenting style. In addition, the relatively high score for self-esteem measures obtained for the adolescents who perceived their parents' style of parenting as authoritative, indicate a preference for authoritative parenting style in this population. Williams also showed that less behavioral inhibition or high self-esteem in children were associated with authoritative parenting $[25,26]$. On the other hand, parenting styles were an objective factor that could influence subjective well-being [27] and affects the child's self-esteem levels [28]. In this study, students from authoritative parenting homes had higher self-esteem than the others. Perhaps this was due to the improved relationship between the visually impaired adolescents and their authoritative parents as noted previously [16], as well as the parent's encouragement of self- 
reliance brought about by authoritative parenting style. Herz and Gullone in 1999 [29] examined the relationship between parental style and self-esteem among 238 normally sighted Australian and Vietnamese adolescents, aged 11-14. They found that a parental style that was characterized by overprotection and low levels of acceptance was negatively associated with self-esteem. In contrast, Bartle et al in 1989 [30] found that a parental style that balances between individual separateness and familial connectedness was associated with high levels of self-esteem and in another study, parental acceptance, approval, and support had positive effects on the young adults' self-esteem [31]. While these studies further show the differences in findings, they were conducted more a decade ago and their findings do not be portray the current situation.

The present study found no significant association between parental style and self-esteem of the visually impaired adolescents which was not in agreement with a previous study conducted among a sample of 31 young adults from a vision rehabilitation agency in the greater New York area which found that both young adults' and mothers' reports of parenting styles were related to self-esteem [32].The difference between our study and the previous study may be related to the differences in culture or environment which influence peoples perceptive [19] and/or the fact that only mothers of the visually impaired adult were surveyed in the previous study [32]. The present study found no differences in responses between the public schools and the school for the visually impaired adolescents for the Tennessee Self Concept Score (TSCS) even though the public-school students had slightly higher self-esteem score $(44.0 \%)$ than the visually impaired students $(35.7 \%)$. This may be influenced by the smaller number of participants from AlNoor Institution as compared with the public schools, but it agrees with a previous study that found the barriers of physical education for the visually impaired students was not dependent on the type of school they attended [33]. The findings of this study provide recent evidence on the attitude and perception of parents and their visually impaired children based on the perception of the Saudi population Unlike a previous study that considered only the mothers, the present study explored the relationships between the permissive, authoritarian, and authoritative parenting styles of both parents, and the self-esteem of young adults with visual impairments and examined both the young adults' and parents' perceptions of their parenting styles, an area that has remained largely unexplored particularly from a category of people with disability.

The findings could improve our understanding of the perceptions of the visually impaired adolescent and may help motivate new projects more accurately targeted to help visually impaired adolescents live more independently in their everyday lives. Another strength of the present study was the utilization of the TSCS-2 to measure the young adults' self-esteem, which is a widely used standardized measurement tool. Despite these strengths, the study had some limitations including that it was conducted in a specific population of Arabs and had relatively low sample size although higher than a previous study [32]. These have implication in the generalizability of the findings and as such the results must be interpreted with cautious, and future studies should consider using a larger and random, sample. In summary, a majority of the visually impaired students (males and females, alike) perceived their parents as being authoritative, had higher self-esteem scores than the fewer students who felts their parents were either authoritarians or permissive and had low self-esteem scores. Further testing on visually impaired adolescents to elicit separate responses for mothers and fathers parenting styles could help reinforce these findings.

\section{Acknowledgement}

Supported by the Research Centre, of the Female Scientific and Medical Colleges, Deanship of Scientific Research at King Saud University.

\section{Conflicts of Interest}

The authors declare no conflict of interests regarding the publication of this paper.

\section{References}

1. Resnikoff S, Pascolini D, Etyaale D, Kocur I, Pararajasegaram R, et al.(2004) Global data on visual impairment in the year 2002. Bulletin of the World Health Organization 82(11): 844-851.

2. Salminen AL, Karhula ME (2014) Young persons with visual impairment: Challenges of participation. Scandinavian Journal of Occupational Therapy 21(4): 267-276.

3. Agran M, Achola E, Nixon CA, Wojcik A, Cain I, et al. (2017) Participation of Students with Intellectual and Developmental Disabilities in Extracurricular Activities: Does Inclusion End at 3:00? Education and Training in Autism and Developmental Disabilities 52(1): 3.

4. Huurre T, Aro H (1998) Psychosocial development among adolescents with visual impairment. European Child \& Adolescent Psychiatry 7(2): 73-78.

5. Koster M, Pijl SJ, Nakken H, Van Houten E (2010) Social participation of students with special needs in regular primary education in the Netherlands. International Journal of Disability, Development and Education 57(1): 59-75.

6. Pijl SJ, Frostad P, Flem A (2008) The social position of pupils with special needs in regular schools. Scandinavian Journal of Educational Research 52(4): 387-405.

7. Pinquart M, Pfeiffer JP (2011) Associations of extroversion and parental overprotection with forming relationships with peers among adolescents with and without visual impairments. Journal of Visual Impairment \& Blindness 105(2): 96.

8. Bal M, Sattoe J, Schaardenburgh N, Floothuis M, Roebroeck M (2017) A vocational rehabilitation intervention for young adults with physical disabilities: participants' perception of beneficial attributes. Child: care, health and development 43(1): 114-125.

9. Seligman M, Darling RB (2009) Ordinary families, special children: A systems approach to childhood disability: Guilford Press.

10. Green SE (2003) “What do you mean 'what's wrong with her?'”: Stigma and the lives of families of children with disabilities. Social Science \& Medicine 57(8): 1361-1374.

11. Reinhardt JP (1996) The importance of friendship and family support in adaptation to chronic vision impairment. The Journals of Gerontology Series B: Psychological Sciences and Social Sciences 51(5): P268-P278. 
12. Lee LW, Low HM (2014) The evolution of special education in Malaysia. British Journal of Special Education 41(1): 42-58.

13. Kroksmark U, Nordell K (2001) Adolescence: The age of opportunities and obstacles for students with low vision in Sweden. Journal of Visual Impairment \& Blindness (JVIB) 95(04).

14. Kef S, Dekovic M (2004) The role of parental and peer support in adolescent's well-being: a comparison of adolescents with and without a visual impairment. J Adolesc 27(4): 453-466.

15. Sinha D, Verma N, Hershe D (2016) A Comparative study of parenting styles, parental stress and resilience among parents of children having autism spectrum disorder, parents of children having specific learning disorder and parents of children not diagnosed with any psychiatric disorder.

16. Baumrind D (1991) The influence of parenting style on adolescent competence and substance use. The Journal of Early Adolescence 11(1): 56-95.

17. Diaconu-Gherasim LR, Măirean C (2016) Perception of parenting styles and academic achievement: The mediating role of goal orientations. Learning and Individual Differences 49: 378-385.

18. de Laat S, Freriksen E, Vervloed MP (2013) Attitudes of children and adolescents toward persons who are deaf, blind, paralyzed or intellectually disabled. Res Dev Disabil 34(2): 855-863.

19. Nagata Y (2016) Fostering Alternative Education in Society: The Caring Communities of "Children's Dream Park" and "Free Space En" in Japan. In: The Palgrave International Handbook of Alternative Education: Springer pp. 241-256.

20. Crews JE, Campbell VA (2004) Vision impairment and hearing loss among community-dwelling older Americans: implications for health and functioning. American journal of public health 94(5): 823-829.

21. (2017) Organization WHO Depression and other common mental disorders: global health estimates.

22. Buri JR (1991) Parental authority questionnaire. J Pers Assess 57(1): 110-119.

ISSN: 2574-1241

DOI: 10.26717/BJSTR.2019.19.003363

Osuagwu Uchechukwu. Biomed J Sci \& Tech Res

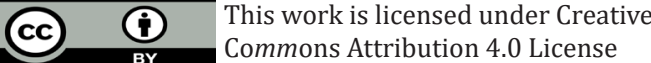

Submission Link: https://biomedres.us/submit-manuscript.php
23. Fitts WH, Warren WL (1996) Tennessee self-concept scale: TSCS-2: Western Psychological Services Los Angeles.

24. Osuagwu UL, Ogbuehi KC, Almubrad TM (2013) Assessing the role of optometrists in the control of systemic hypertension in Saudi Arabia. J Am Soc Hypertens 7(4): 305-316.

25. Williams LR, Degnan KA, Perez-Edgar KE, Henderson HA, Rubin $\mathrm{KH}$, et al. (2009) Impact of behavioral inhibition and parenting style on internalizing and externalizing problems from early childhood through adolescence. Journal of Abnormal Child Psychology 37(8): 1063-1075.

26. Williams KL, Wahler RG (2010) Are mindful parents more authoritative and less authoritarian? An analysis of clinic-referred mothers. Journal of Child and Family Studies 19(2): 230-235.

27. Wang Y, Jiang ZP (2016) Effect of Parenting Styles and Self-Esteem on Subject Well-being among Chinese Medical Students. International Forum of Teaching and Studies: American Scholars Press, p. 26.

28. Papadopoulos K, Montgomery AJ, Chronopoulou E (2013) The impact of visual impairments in self-esteem and locus of control. Research in developmental disabilities 34(12): 4565-4570.

29. Herz L, Gullone E (1999) e-Relationship between Self-Esteem and Parenting Style: A Cross-Cultural Comparison of Australian and Vietnamese Australian Adolescents. Journal of Cross-Cultural Psychology 30(6): 742-761.

30. Bartle SE, Anderson SA, Sabatelli RM (1989) A model of parenting style, adolescent individuation and adolescent self-esteem: Preliminary findings. Journal of Adolescent Research 4(3): 283-298.

31. Buri JR, Kirchner PA, Walsh JM (1987) Familial correlates of self-esteem in young American adults. Journal of Social Psychology 127(6): 583-588.

32. Cardinali G, D’Allura T (2001) Parenting styles and self-esteem: A study of young adults with visual impairments. Journal of Visual Impairment \& Blindness 95(5): 261-271.

33. Lieberman LJ, Houston-Wilson C, Kozub FM (2002) Perceived barriers to including students with visual impairments in general physical education. Adapted Physical Activity Quarterly 19(3): 364-377.

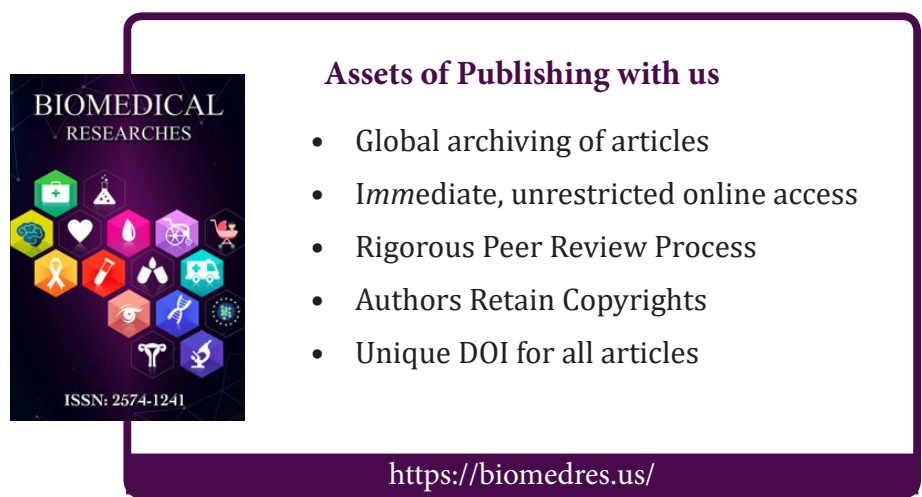

